\title{
The clinical characteristics of pain in patients with pituitary adenomas
}

Dimopoulou C, Athanasoulia AP, Hanisch E, Held S, Tölle T, Sprenger T, Zieglgänsberger W,

Pfister H, Römmler J, Schopohl J, Stalla GK \& Sievers C

Clinical presentation of pituitary adenomas frequently involves pain, particularly headache, probably due to both structural and functional properties of the tumour.

\section{Methods}

In a retrospective analysis, we investigated clinical characteristics of pain in $\mathbf{2 7 8}$ patients with pituitary disease ( $\mathrm{n}=\mathbf{8 1}$ acromegaly; $n=45$ Cushing's disease; $n=92$ prolactinoma; $n=60$ non-functioning pituitary adenoma) presenting with any kind of pain between 1990 and 2012. Specific pain patterns were measured using three standardized pain questionnaires, the DSF

(Deutscher Schmerz Fragebogen), the MIDAS (Migraine Disability Assessment) and the painDETECT questionnaire.

Results

\begin{tabular}{|c|c|c|c|c|c|c|c|c|c|c|}
\hline Demography & All pa & ients & Acror & egaly & $\mathrm{C}$ & & Prolac & inoma & NF & \\
\hline & $n=$ & & & & $\mathrm{n}=$ & & & & $\mathrm{n}=$ & \\
\hline & $N$ & $\%$ & $\mathrm{~N}$ & $\%$ & $\mathrm{~N}$ & $\%$ & $N$ & $\%$ & $N$ & $\%$ \\
\hline Sex & & & & & & & & & & \\
\hline - Male & 108 & 38,8 & 38 & 46,9 & 8 & 17,8 & 23 & 25 & 39 & 65 \\
\hline -Female & 170 & 61,2 & 43 & 53,1 & 37 & 82,2 & 69 & 75 & 21 & 35 \\
\hline & Mean & $\mathrm{SD}$ & Mean & $\mathrm{SD}$ & Mean & $\mathrm{SD}$ & Mean & $\mathrm{SD}$ & Mean & $\mathrm{SD}$ \\
\hline Age & 52,8 & 13,2 & 55,5 & 11,8 & 46,2 & 11,1 & 49,2 & 13,8 & 60,2 & 10,6 \\
\hline Tumour character & & & & & & & & & & \\
\hline - macroadenoma & 163 & 58.6 & 53 & 65 & 15 & 33.3 & 45 & 48.9 & 50 & 83 \\
\hline - microadenoma & 87 & 31,3 & 6 & 7 & 30 & 66,7 & 47 & 51,1 & 4 & 7 \\
\hline - no data available & 28 & 10,1 & 22 & 28 & & & & & 6 & 10 \\
\hline Treatment & $\mathrm{N}$ & $\%$ & $\mathrm{~N}$ & $\%$ & $\mathrm{~N}$ & $\%$ & $\mathrm{~N}$ & $\%$ & $\mathrm{~N}$ & $\%$ \\
\hline - surgery & 182 & 65,5 & 73 & 90,1 & 44 & 97,8 & 13 & 14,8 & 52 & 86,7 \\
\hline - radiotherapy & 51 & 18,3 & 20 & 24,7 & 14 & 31,1 & 2 & 2,3 & 15 & 25,0 \\
\hline
\end{tabular}

Table 1 Clinical characteristics of the study population.

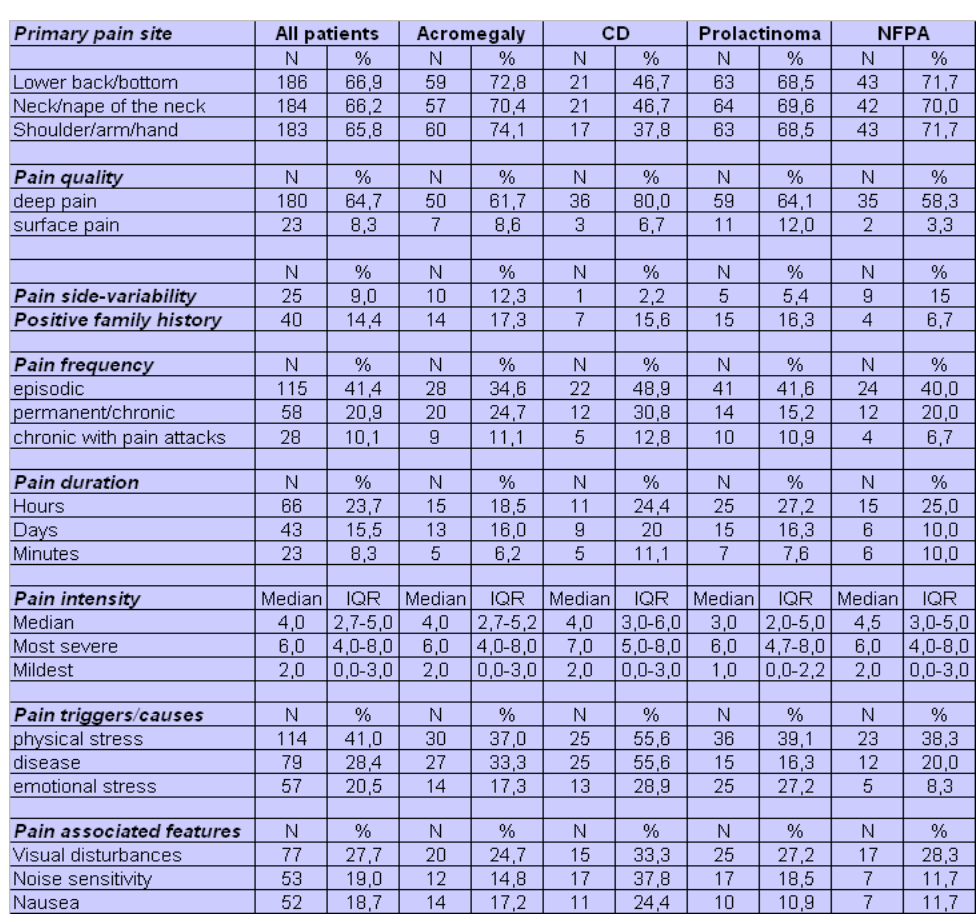

Table 2 Pain characteristics according to DSF.

Conclusions / Discussion

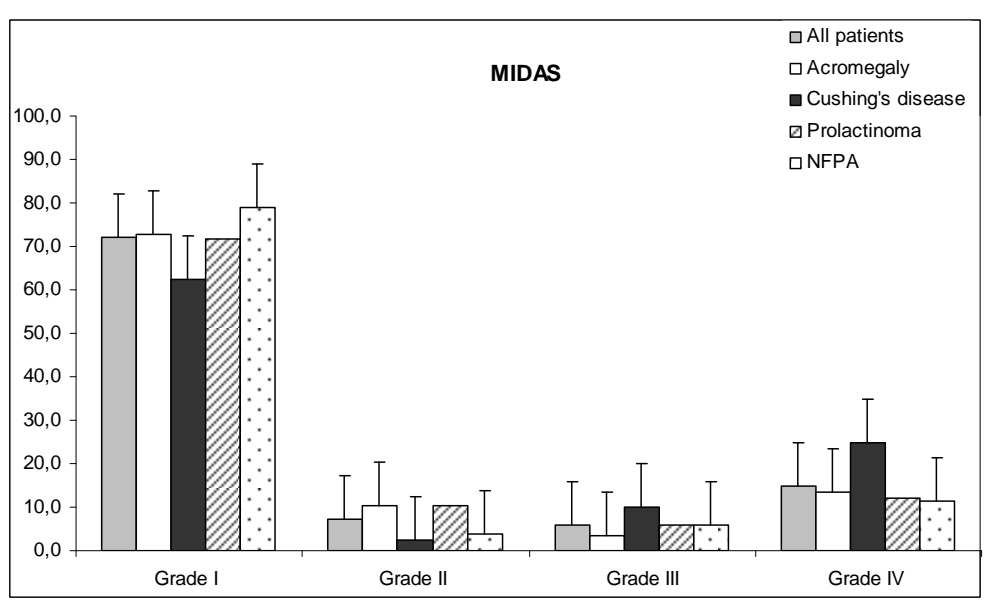

Figure 1 Distribution of MIDAS scores in the overall study population and according to each tumour subtype. Mean MIDAS score for the whole group were $12.1 \pm 33.3$ days. The majority of the patients (72\%) presented with little or no migraine-related disability (Grade I).

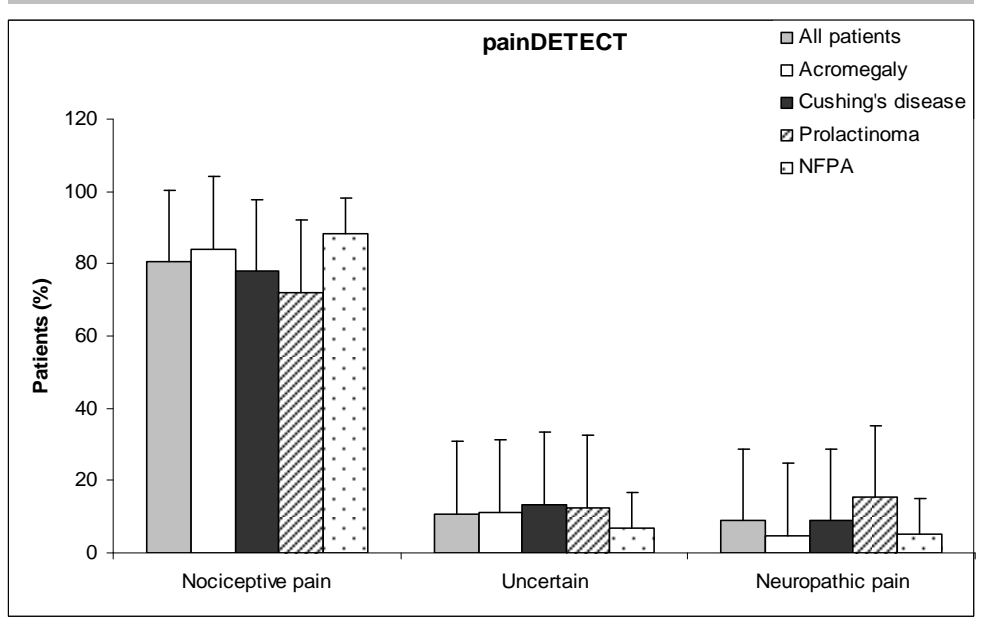

Figure 2 Distribution of painDETECT scores in the overall study population and according to each tumour subtype. Mean painDETECT score was 7.4 \pm 7.1 . The majority of the patients suffered from nociceptive pain $(80.4 \%)$.

\section{Literature}

- Pain appears to be a significant problem in pituitary disease and is associated with a range of pain phenotypes.

- A combination of factors including tumour activity, cavernous sinus invasion, as well as previous predisposition to pain might play a role in pain phenotypes.

Stewart et al. Pain 2000; 88:41-52

- Nagel et al. Schmerz 2002; 16:263-270

- Levy et al. Brain 2005; 128:1921-1930

- Freynhagen et al. Curr Med Res Opin 2006; 22:1911-1920

MPI of Psychiatry - Kraepelinstraße 2-10, 80804 Munich 